\title{
Evolving international academic exchanges: The shifting cross-strait university practices between Taiwan and China
}

Chou, Chuing Prudence $\varangle$

Department of Education, National Chengchi University, Taiwan (iaezcpc@nccu.edu.tw)

Ching, Gregory S.

Graduate Institute of Educational Leadership and Development

Research and Development Center for Physical Education, Health, and Information Technology

Fu Jen Catholic University, Taiwan (gregory_ching@yahoo.com)

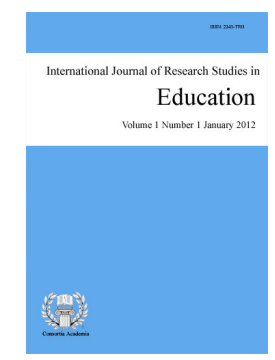

ISSN: 2243-7703 Online ISSN: 2243-7711

OPEN ACCESS

\section{Abstract}

International academic exchanges have long portrayed a pivotal role in higher education internationalization. Within the Taiwan model, a distinct feature of international academic exchanges is the cross-strait (Taiwan and Mainland China) university practices. To highlight the recent changes within cross-strait university practices, this paper shall focus on the analysis of various scholarly relations between Taiwanese scholars and their Mainland Chinese counterparts. Several interviews with 14 scholars were accomplished highlighting the various patterns of interactions under the different dimensions of collaborations between Taiwanese and Mainland Chinese academics. In addition, challenges within the various cross-strait university practices were also provided. In essence, as China's economy develops, its higher education quality improves and so as with their students and academics. In contrast, the shrinkage of academic funding in Taiwan is followed by a sense of anxiety within the academe.

Keywords: international education; higher education in China and Taiwan; cross-strait relationship; university faculty; international cooperation; academic exchange 


\section{Evolving international academic exchanges: The shifting cross-strait university practices between Taiwan and China}

\section{Introduction}

Within the vast literature of internationalization of higher education, academic exchanges have long portrayed a pivotal role within the structures and practices of Western higher education, particularly in European countries, the United States, Canada, Australia, and New Zealand (for more details please see, Daly \& Barker, 2005; Eldridge \& Wilson, 2003; Meiras, 2004; Peters, 2003; Rizvi \& Walsh, 1998; Robertson \& Webber, 2000; Saffu \& Mamman, 1999; Webber \& Robertson, 1998, 2003, 2004). In contrast, studies of this phenomenon in Asia have historically been underrepresented. However, recently there has been a growing interest in the understanding of the greater Chinese society, including Hong Kong, China, Taiwan, and Singapore. These are actually manifested within the context of developing comparative education research in the Chinese context (Bray \& Qin, 2001; Harding, 1995).

A quick literature review check have shown that a number of scholars have endeavored to investigate the practices and outcomes of initiatives in higher education in Singapore, Hong Kong, and China (for more details please see, Chan \& Postiglione, 1996; Gopinathan, 2001; Mok \& Lee, 2000; Mok \& Tan, 2004; Mok \& Welch, 2003; Ngok \& Kwong, 2003; Post, 2003; Sanderson, 2002; Selvaratnam, 1994). Within the Taiwan perspective, very limited literature discussed the various practices and impacts of change on higher education institutions. In addition, the recent drive for regional cooperation among higher education institutions within and beyond the Asia region has altogether created a sort of win-win strategic situation in teaching and research development (Kwok, 2017). Hence, understanding the various underlying changes within the current cross-strait academic exchanges between Taiwan and China is considered to be quite important.

With this in mind, the current study uses a qualitative research paradigm and investigates the various scholarly relations between Taiwanese academics and their Mainland Chinese counterparts. A total of 14 scholars from a top tier university in Northern Taiwan were interviewed. Semi-structured interview method was used in order to best collect and understand the various issues within academic exchanges (Bernard, 1988). Interview method can also be considered to be a two-way approach, wherein the interviewee and interviewers are able to better clarify the issue at hand (Adams, 2015). Interview schedules were semi-structured to allow for flexibility to explore different issues as they arose. Initial interview question asked were regarding the scholar's perceived patterns and approaches to academic exchanges between Taiwan and Mainland China. Interviews lasted from around 60 to 90 minutes and were conducted in Chinese and later on translated into English (for this report). Venues of the interviews are mostly in the participants' office. Informed consent are provided and signed.

Participants selected for the study are based on several criteria. First, scholars who are selected for the interviews should at least be affiliated with a higher education institutions for not less than five years; Second, participants should have in more than one occasion participated or undertaken cross-strait academic exchange activities (in other words, scholars must have a history of familiarity or active interactions with Mainland and other Chinese scholars). In addition, in order to collect data from a wide range of disciplines and academic ranks, the 14 scholars are strategically selected from the following colleges: five (5) from the College of Social Sciences, one (1) from the College of Liberal Arts, two (2) from the College of Science, two (2) from the College of Management, one (1) from the College of Bio-Resources and Agriculture, and three (3) from the College of Engineering.

Demographics of the scholars included participants who obtained their doctoral degrees from higher education institutions mostly in the United States. Majority of the scholars, around eleven scholars, had pursued their doctoral studies during the 1970s and 1980s, and they were within the 40-65 age range. The youngest one 
was 38 years of age and had conducted her doctoral study during the 1990s. Lastly, collected data from the interviews are analyzed using the Miles and Huberman (1994) method for generating meaning from transcribed and interview data. Patterns from the scholars' response are noted, while Glaser's (1978) notion of constant comparison was also used when reviewing previous study abroad studies, subsuming particulars into generals, and forming similar categories into indicators.

\section{Internationalization of Taiwan higher education}

Internationalizing higher education institutions has become increasingly important, complex, and confusing (Knight, 2004). The formation of globally-oriented policies and agreements by international agencies can be seen as the member nations' collective response to the demand for enhancing national competitiveness (Marginson, 1997). Some of these international agencies that further hasten and strengthen internationalization of higher education are, for example, the Organization for Economic Co-operation and Development (OECD), United Nations Educational, Scientific and Cultural Organization (UNESCO), Asia-Pacific Economic Cooperation (APEC), World Trade Organization (WTO), and University of Mobility in Asia and the Pacific (UMAP). Under these multi-dimensional and dynamic influences, both traditional and new providers of higher education have adopted international cooperation in order to build the capacity and competency of the institution, seek resources internationally for staff and student development, and cope with changing global trends and agendas (Abbott, 2006; Marginson, 1997; Peters \& Roberts, 1999; Yang, 2003, 2004).

In response, Taiwan has placed a strategic priority on higher education to reinforce its global competitiveness and build a knowledge-based economy. They have endeavored to increase the capacity of top universities, particularly prestigious public institutions. The current reform policy on upgrading the capacity and quality of higher education in Taiwan, therefore, targets only a small number of top universities with the goal of assisting them in entering the realm of the so-called top 100 world-class universities. Higher education institutions in Taiwan are, on the one hand, expected and obligated to represent the identity of the nation and the individuality of the institution. On the other hand, they are placed in the market of global competition as a result of internationalization, globalization, and marketization in the Asia-Pacific region (Mok \& Welch, 2003).

The change in legal restrictions in Taiwan's higher education has helped to promote a diversified system and allow for greater autonomy in appointing presidents, charging tuition fees, offering courses, and recruiting students. Recently, debate has arisen over what constitutes the top 100 world-class universities, who defines it, and according to whose standards. Without a doubt, universities in Taiwan, even the most prestigious ones, have been in the process of striving to internationalize their professoriates. Hence, understanding academic exchanges is a key step in further enhancing the internationalization capacities of higher education institutions in Taiwan.

\section{Patterns of cooperation}

\subsection{Contact and communication}

From the interview results, it is noted that most participants maintained a good connection with overseas colleagues within the following formats: attending international conferences, presenting papers, publishing journal articles or co-authoring books, serving as journal editorial committee members, doing academic exchanges, and collaborating on research projects. Contact remains constant between Taiwanese and Chinese faculty through mutual visitation, writing letters, meetings, and conferences. Furthermore, most political scientists expressed their some-what frustration when dealing with their Chinese colleagues owing to the sensitivity of their research topics regarding government policy analysis. Hence, participants noted that mutual trust and academic freedom are somewhat interfering with cross-strait relations.

Participants consider there is no problem in communication with overseas Chinese thanks to their compatible academic convention. Although Chinese scholars had hidden agenda in political ideology before the 
1980s, they have become more and more open and well-informed as China's opening-up. In terms of research framework, research methodology, and publication criteria, Chinese academics have much to catch up, but the gap is narrowing down. Lastly, participants also express their concern and mixed feeling about their own situation compared with their Chinese counterparts, and is aware of the declining demands in China for Taiwan's expertise.

\subsection{Cross-strait exchanges}

Many of the participants were known by their Chinese colleagues because of their academic works that were highly cited, which are also compiled in volumes of books (reprinted) in China, especially in the fields of science and political science. Few colleagues in business schools initiated exchanges in which they took turns hosting annual events such as academic debate/contests, financial prediction workshops, and campus exchange visits among these universities. Most participants did not publish articles or books in China, except for one or two that were reprinted in compiled book volumes or Chinese journals. The contacts with overseas Chinese scholars were much more transparent, efficient, and academically oriented, because of their compatibility with Western academic training backgrounds and publication conventions, research rationale, theory, style, and methodology. In addition, there are more collaborated research and publication projects between participants and overseas Chinese than with Mainland Chinese counterparts.

Participants with a foreign highest degree (usually an American one) tend to continue their existing network with international/American academic community and thus, will attend more international or regional conferences than those with a domestic degree. Interestingly, the only participant with a domestic highest degree was among the most active cross-strait exchangers, which attended more than fifteen cross-strait conferences during the last five years. The other one invited more than 50 overseas scholars to Taiwan, thanks to his administrative position and establishment in political sciences. Most of the faculty taught Chinese and overseas students in rare occasions under short-term exchanges. They were asked for thesis consultancy, usually when students were invited to Taiwan to do their field-study on Taiwan or to attend conferences, meetings, forums or other academic activities. Lastly, none of the participants ever supervise Chinese or overseas students as thesis advisors.

\subsection{Career development in Taiwanese academics}

In Taiwan, each discipline has different requirements for rank promotion and career development. However, in general, Taiwanese faculty tends to spend more time between rank promotions and remain working in the academe much longer than their Chinese counterparts. Some explanations revealed through interviews are as follows: First, Chinese universities only have three ranks (lecturer, associate professor, and full professor), which make Chinese faculty more flexible and quicker to be promoted. Second, Taiwanese academic promotion criteria have been mainly based on academic publications (articles/research work published in indexed journals, such as Thomson Reuter's Social Science Citation Index; SSCI, Science Citation Index; SCI, and Engineering Index; EI or Compendex), for the past five years, which has made rank promotion less accessible and more competitive for Taiwanese junior faculty than their Chinese counterparts who might be new PhDs graduates from abroad (the US and UK). Third, Taiwanese colleagues are required to assume a bigger workload in teaching, conducting research, community service, and inter- or intra-university service that they do not get credit for. During the past 2-3 years, Taiwanese faculty members have been going through a series of internal and external evaluations focused on accountability. This has taken up a great proportion of their time and energy and resulted in tremendous pressure on junior participants.

\subsection{Recent developments}

There has been an increasing trend of university student exchanges between Taiwan and China because of increasing sponsorship by governments, private corporations, foundations and NGOs in the last ten years. This

4 Consortia Academia Publishing (A partner of Network of Professional Researchers and Educators) 
has enabled them to invite more research collaboration from abroad and Taiwan, and to host more conferences. Interviewees have witnessed a drastic change in academic working conditions in China since the 1990s when China adopted a market-economy ideology and restored its higher education system. An increasing number of Chinese faculty are engaging in activities by hosting or attending international conferences, conducting exchange visits, and setting up new programs between Chinese and foreign universities. In atmospheric science there used to be four types of cross-strait exchange activities: First, academic exchange; Second, technical exchange; Third, information exchange; and fourth, jargon exchange for compatible terms. Whereas universities used to take the initiative in Taiwan, government officials were in charge of the cross-strait exchanges for China. Now the situation has changed, and more and more Chinese universities are engaging with the outside academe. In this sense, Taiwan is losing its former strength from when most faculty members were foreign-trained and continued to network with international acquaintances.

\subsection{Overall impressions}

It is meaningful and fruitful for keeping the cross-strait academic dialogue active and open regardless of the political difficulties at the current moment. In terms of academic standard, research resources, and openness to the international exchanges, Chinese academe is making drastic progress in the past decade which has rendered a great transformation in higher education across the country. Although China still has censorship in political, social, and academic arena, most major universities have set up academic exchange and even memorandums/contracts with overseas institutions, hence, increasing their internationalization competitiveness.

\section{Challenges in cross-strait exchanges}

\subsection{The dominance of US qualifications in academia}

The academic work and career development of Taiwanese scholars varied across disciplines. However, most participants noted two clear pathways after the Taiwanese scholars had finished their doctoral studies (mostly in abroad). First, is to return home to Taiwan after graduation; Second, is teaching or working abroad (mostly in Western countries like the US) for a couple of years then returning to Taiwan. The former comprised the largest number of Taiwanese scholars whereas only a few had a period of work experience in the host country prior to their return. The researchers were aware of this phenomenon as it reflected the demand for Western or primarily US trained human resources in Taiwan and Mainland China.

On the one hand, the dominance of US educated scholars at the academia had lent hands to secure the relationships between US and Taiwanese/Chinese institutions. On the other hand, there is a danger of promoting Western or US agenda and ideologies through the university curriculum and research. This actually needs Chinese scholars' caution and awareness that the internationalization of Taiwanese and Chinese institutions should not become synonymous of that to the 'Americanization' through academic activities. In particular, one scholar at the Department of Psychology further noted the impact of overseas study experience on his understanding of Western cultures. It would be worth exploring whether other scholars had developed their ability in critical thinking and reflection, in addition to their research skills, arising from the US study abroad experiences.

\subsection{The role of government and economic growth}

Prestigious Taiwanese as well as Chinese universities have traditionally had the privilege of obtaining additional funding from the central and local governments. The Chinese Development Foundation has played a crucial role since 1996 in providing various programs sponsoring the cross-strait exchanges among university faculty and graduate students. Many participants invited their Chinese colleagues and students over to their universities through this funding source and vice versa. However, the government budget for supporting Taiwanese graduates' data collection in China was vetoed and discontinued on 2005 by the Legislature Yuan, due 
to suspicion about the political and economic effectiveness of such exchanges, especially in a period of government budget constraints. Criticism about the cancellation soon followed, and the program was reintroduced the following year. This instability and vulnerability of academic exchange support from the government highlights the sensitivity of the current situation at the Taiwanese and Chinese government policy level and has threatened the continuity of cross-strait academic exchanges.

On the other hand, Taiwanese funding opportunities have become more and more limited which reversed the exchange pattern between Taiwan and China. Chinese academe has changed to a great extent and many leading universities (such as Beijing University), which considered international academic exchanges (including with Taiwan) a priority for their university's improvement. Unlike China's rapid economic growth during the past two decades, Taiwan's economic growth was relatively limited. This together with the expansion of higher education institutions in Taiwan, as discussed earlier in the paper, has placed enormous financial burden on both public and private institutions, impacted the evaluation systems, and shifted the focus of the profession.

Citing a comment by a Political Science professor:

...the declining economic development since late 1990s, coupled with the drastic higher education expansion and shrinking public funding, most Taiwanese universities encountered budgetary shortage and, therefore, were driven to create external revenue. More and more higher education institutes are geared toward market-economy than for education and research. Along with the ongoing competition between China and Taiwan for academic excellence, more and more financial pressure has resulted in many unprecedented challenges to the university. The current inter-collegiate evaluation system based on the sole-criteria, publication from SSCI, SCI, and EI, has brought up an extra burden on faculty members who, nowadays, engaged more in external funding resources than pure research and serving as public intellectuals. This market-driven stress has impaired many faculty health conditions such as burn-outs, or unexpected illness... PS003

In particular, reform projects that linked funding and promotion scales have had tremendous impacts on the profession and will be detailed in the next section.

\subsection{Projects linked with funding and promotion scales}

When compared to Mainland China, the practice of salary and promotion scales in the Taiwanese academia would have followed a more structural and controlled system that required scholars to develop their careers along three steps (assistant professor, associate professor, and full professor), during a specified period of time and based on the quantity of their publications. Nevertheless, some participants noticed that not only Taiwanese professoriate would require indexed (such as SSCI or SCI) publications as part of the promotional criteria, but their mainland counterparts have started to pay attention to research publications and teaching, which had not been the priority since the start of the Chinese economic reform.

When the university is targeted for world class status, and has been required to establish an evaluation system which integrates standards such as the SSCI, SCI, EI, or equivalent international recognition for awards, achievements, and contributions within their fields of expertise. Because of the university evaluation demands, many overseas Chinese scholars were invited to sit on the evaluation/review committee, or to participate in special research projects. It was a two-way exchange since participants are also requested to do the same thing.

Similarly, the Chinese government has launched two major projects, namely '211 Project' in 1995 and '985 World-Class University Project' in 1998, with an attempt to enhance international competitiveness of Chinese universities. The former project entails a wide selection of one hundred universities throughout the country that would apply for funding based on a number of assessment criteria, for example the number of faculty, facilities, libraries, laboratories, and research quality; whereas the latter has continued to concentrate high-level funding

6 Consortia Academia Publishing (A partner of Network of Professional Researchers and Educators) 
which are additional to the '211 Project' on a much smaller number of top universities, for example ten universities in 1998 and 30 universities in 2004. These movements jointly lead to a series of institutional merger and help to reposition Chinese institutions in research, publications and teaching. Many Taiwanese scholars were aware of those reform movements in China and one Building and Planning professor commented:

Chinese scholars have started to concentrate on research after the implementation of the '211 Project' with the increase of funding on targeted or so-called prestigious universities... PB001

Such evaluation system that weaves funding scales with research publications, however, is under the criticism of exaggerating the workload of seeking opportunities for research projects, and publishing for the sake of publishing within the academia.

\subsection{Divergent academic paradigms}

One major theme that arises during the interviews is the issue of political control over communication freedom. Some participants revealed concerns regarding printed materials in the post or emails containing words or phrases that are politically sensitive and consequently be blocked by the mailing system. For instance, an Accounting professor commented that there was internet control that prevented scholars in Mainland from accessing Taiwanese websites and online databases. Yet, another participant further highlighted that only top tier universities in China emphasized the development of internet communication. Such information control or filter system can be considered as one of the major problem that would hinder cross-strait academic exchange.

As a result, local scholars have developed their political sensitivity when interacting with their Chinese professoriate counterparts. They tend to avoid co-authoring books or journal articles with the Chinese counterparts. It is also uncommon for scholars to examine papers or thesis which were written by Chinese scholars or research students. Supervising Chinese research students are also rare. However, many of them had hosted a number of visiting scholars and student groups from the Mainland, which is due to various institutional partnership arrangements with several prestigious universities in China.

This political sensitivity was also reflected during the course of the interviews. A scholar from the Political Science department and another one from the Civil Engineering department both noted that only limited interactions between their Chinese counterparts. Involvement such as attending a conference in Mainland China, published an article/chapter in a Mainland publication; co-author an article or chapter with a colleague from Mainland; examined a thesis from the Mainland; taught students from Mainland; and invited a Mainland colleague to Taiwan, are all considered as sensitive issues. This is somewhat surprising that even within local participants; political sensitivity is also an issue. On the contrary, some participants felt that during the past five years, there is a significant growth in terms of academic freedom in China. For example, they noticed that Chinese scholars could now disagree with their governments in conferences or public occasions which would be impossible during the past ten years.

Lastly, within academic research quality, many participants commented that the academic traditions in China, for example referencing styles and article formats, were loosely regulated when compared with those in Taiwan. In particular, one Agriculture Economics professor pointed out some features of the academic traditions in China. He said academic writings in China were usually short, rarely using statistical methods, primarily involving narratives and policy analysis, and lacking multiple angles of analysis. However, the authors of this report argued that these perceived gaps should be addressed when cooperating with their Chinese counterparts, but these should not be a barrier to understanding and recognizing their research outcome or achievements.

\section{Conclusion}

The primary objective of the current paper is to highlight the various patterns of interactions and different dimensions of collaborations between Taiwanese and Mainland Chinese academics. Results highlighted various 
dimensions that are quite distinct to cross-strait exchanges. Starting with the issues of political sensitivity of cross-strait dialogue and exchange activities between Taiwan and Mainland China; to the uneven challenges within the academe itself, changes have been observed coming from both sides of the strait. The phenomenon of visiting Taiwan for Chinese faculty and graduate students has been more popular than the other way around. On the other hand, an increasingly reverse discrepancy among Taiwanese and Chinese academic qualifications and talents has aroused some concerns among the participants. This reverse discrepancy is reflected not only within the career development of academics, but also within the various academic paradigms. Lastly, as China's economy progresses, higher education quality improves, and so as the academics and students. A sense of anxiety and worry about the declining academic funding and academic quality in Taiwan is common among the study participants when comparing with their Chinese counterparts.

\section{References}

Abbott, M. (2006). Competition and reform of the New Zealand tertiary education sector. Journal of Education Policy, 21(3), 367-387. https://doi.org/10.1080/02680930600600663

Adams, W. C. (2015). Conducting semi-structured interviews. In K. E. Newcomer, H. P. Hatry, \& J. S. Wholey (Eds.), Handbook of practical program evaluation (4th ed., pp. 492-505). San Francisco, CA: Jossey Bass. https://doi.org/10.1002/9781119171386.ch19

Bernard, H. R. (1988). Research methods in cultural anthropology. Newbury Park, CA: Sage.

Bray, M., \& Qin, G. (2001). Comparative education in greater China: Contexts, characteristics, contrasts and contributions. Comparative Education, 37(4), 451-473. https://doi.org/10.1080/03050060120091256

Chan, M. K., \& Postiglione, G. A. (Eds.). (1996). The Hong Kong reader: Passage to Chinese sovereignty. Armonk, NY: ME Sharpe.

Daly, A. J., \& Barker, M. C. (2005). Australian and New Zealand university students' participation in international exchange programs. Journal of Studies in International Education, 9(1), $26-41$. https://doi.org/10.1177/1028315304271479

Eldridge, D. A., \& Wilson, E. M. (2003). Nurturing knowledge: The UK higher education links scheme. Public Administration and Development, 23(2), 151-163. https://doi.org/10.1002/pad.269

Glaser, B. G. (1978). Theoretical sensitivity: Advances in the methodology of grounded theory. Mill Valley, CA: Sociology Press.

Gopinathan, S. (2001). Globalisation, the state and education policy in Singapore. In J. Tan \& S. Gopinathan (Eds.), Challenges facing the Singapore education system today (pp. 74-87). Jurong, Singapore: Pearson Education South Asia. https://doi.org/10.1080/02188799608542612

Harding, H. (1995). The concept of Greater China: Themes, variations and reservations. In D. L. Shambaugh (Ed.), Greater China: The next superpower? (pp. 8-34). New York, NY: Oxford University Press.

Knight, J. (2004). Internationalization remodeled: Definition, approaches, and rationales. Journal of Studies in International Education, 8(1), 5-31. https://doi.org/10.1177/1028315303260832

Kwok, K.-H. (2017). When education meets politics in Taiwan: A game theory perspective (1994-2016).

Rotterdam, The Netherlands: Sense Publishers. https://doi.org/10.1007/978-94-6351-152-0

Marginson, S. (1997). Markets in education. St. Leonards, NSW: Allen \& Unwin.

Meiras, S. (2004). International education in Australian universities: Understandings, dimensions and problems. Journal of Higher Education Policy and Management, 26(3), 363-380. https://doi.org/10.1080/1360080042000290212

Miles, M., \& Huberman, M. (1994). Qualitative data analysis (2nd ed.). Beverly Hills, CA: Sage.

Mok, K.-H., \& Lee, H.-H. (2000). Globalization or re-colonization: Higher education reforms in Hong Kong. Higher Education Policy, 13, 361-377. https://doi.org/10.1016/S0952-8733(00)00018-0

Mok, K.-H., \& Tan, J. (2004). Globalization and marketization in education: A comparative analysis of Hong Kong and Singapore. Cheltenham, UK: Edward Elgar Publishing.

Mok, K.-H., \& Welch, A. (2003). Globalization, structural adjustment and educational reform. In K.-H. Mok \& A. Welsh (Eds.), Globalization and educational restructuring in the Asia Pacific region (pp. 1-31).

8 Consortia Academia Publishing (A partner of Network of Professional Researchers and Educators) 
Evolving international academic exchanges: Shifting cross-strait university practices between Taiwan and China

Gordonsville, VA: Palgrave Macmillan. https://doi.org/10.1057/9781403990488_1

Ngok, K.-L., \& Kwong, J. (2003). Globalization and educational restructuring in China. In K.-H. Mok \& A.

Welch (Eds.), Globalization and educational restructuring in Asia and the Pacific Region (pp. 160-188).

Gordonsville, VA, USA: Palgrave Macmillan. https://doi.org/10.1057/9781403990488_6

Peters, M. (2003). The New Zealand education experiment: From democratic participation to self-management, and from universal welfare entitlement to private investment. In K.-H. Mok (Ed.), Globalization and educational restructuring in Asia and the Pacific region (pp. 302-332). Gordonsville, VA: Palgrave Macmillan. https://doi.org/10.1057/9781403990488_10

Peters, M., \& Roberts, P. R. (1999). University futures and the politics of reform in New Zealand. Palmerston North, New Zealand: Dunmore Press.

Post, D. (2003). Post-secondary education in Hong Kong: Repercussions for inequality and civil society. Asian Survey, 43(6), 989-1011. https://doi.org/10.1525/as.2003.43.6.989

Rizvi, F., \& Walsh, L. (1998). Difference, globalization and the internationalization of curriculum. Australian Universities Review, 41(2), 7-11.

Robertson, J. M., \& Webber, C. F. (2000). Cross-cultural leadership development. International Journal of Leadership in Education, 3(4), 315-330. https://doi.org/10.1080/136031200750035950

Saffu, K., \& Mamman, A. (1999). Mechanics, problems and contributions of tertiary strategic alliances: The case of 22 Australian universities. The International Journal of Educational Management, 13(6), 281-286. https://doi.org/10.1108/09513549910294487

Sanderson, G. (2002). International education developments in Singapore. International Education Journal, 3(2), 85-103.

Selvaratnam, V. (1994). Innovations in higher education: Singapore at the competitive edge. Washington, DC: The World Bank. https://doi.org/10.1596/0-8213-2618-X

Webber, C. F., \& Robertson, J. M. (1998). Boundary breaking: An emergent model for leadership development. Educational Policy Analysis Archives, 6(21). https://doi.org/10.14507/epaa.v6n21.1998

Webber, C. F., \& Robertson, J. M. (2003). Developing an international partnership for tomorrow's educational leaders. International Studies in Educational Administration, 31(1), 15-32.

Webber, C. F., \& Robertson, J. M. (2004). Internationalization and educator's understanding of educational leadership. The Educational Forum, 68, 264-275. https://doi.org/10.1080/00131720408984638

Yang, R. (2003). Internationalized while provincialized? A case study of South China Normal University. Compare, 33(3), 287-300. https://doi.org/10.1080/03057920302594

Yang, R. (2004). Openness and reform as dynamics for development: A case study of internationalization at South China University of Technology. Higher Education Policy, 47, 473-500. https://doi.org/10.1023/B:HIGH.0000020871.50897.ae 
Chou, C. P., \& Ching, G. S.

10 Consortia Academia Publishing (A partner of Network of Professional Researchers and Educators) 